The Geneva Papers on Risk and Insurance, 22 (No. 85, October 1997), 501-514

\title{
Natural Disasters and the Greenhouse Effect: Impact on the Insurance Industry and Possible Countermeasures
}

\author{
by Dr. Gerhard A. Berz*
}

In the last few decades, the international insurance industry has been confronted with a drastic increase in the scope and frequency of great natural disasters. The trend is primarily attributable to the continuing steady growth of the world population and the increasing concentration of people and economic values in urban areas. An additional factor is the global migration of populations and industries into areas such as coastal regions, which are particularly exposed to natural hazards. The natural hazards themselves, on the other hand, have, in most cases, not yet changed to a statistically significant degree.

In addition to the problems the insurance industry has with regard to pricing, capacity and loss reserves, the assessment of insured liabilities, preventive planning and the proper adjustment of catastrophe losses are gaining importance.

The present problems will be dramatically aggravated if the greenhouse predictions come true. The increasing intensity of all convective processes in the atmosphere will possibly force up the frequency and severity of tropical and extratropical cyclones, tornados, hailstorms, floods and storm surges in many parts of the world with serious consequences for all types of property insurance.

Rates will have to be raised and in certain coastal areas insurance cover will only be available after considerable restrictions have been imposed, as for example significant deductibles and low liability or loss limits. In areas of high insurance density the loss potential of individual catastrophes can reach a level at which the national and

\footnotetext{
*Head of Geoscience Research, Munich Reinsurance Company, D-80791 Munich, Germany.
} 
international insurance industries will run into serious capacity problems. Recent disasters showed the disproportionately high participation of reinsurers in extreme disaster losses and the need for more risk transparency if the insurance industry is to fulfil its obligations in an increasingly hostile environment.

\section{Disaster trends}

During the early 1990s, a remarkable series of major natural disasters taught the insur ance industry bitter lessons it will not forget. Table 1 lists all natural disasters from the past few decades that have cost the insurance industry more than US $\$ 1$ billion. While only one event, Hurricane Alicia, exceeded this figure prior to 1987, the period since 1987 has seen

Table I: Natural Disasters: Billion-\$Insurance Losses

\begin{tabular}{|c|c|c|c|c|c|}
\hline Rank & Year & Event & Area & $\begin{array}{l}\text { Ins. losses } \\
\text { (million US\$) }\end{array}$ & $\begin{array}{l}\text { Economic losses } \\
\text { (million US\$) }\end{array}$ \\
\hline 17 & 1983 & Hurricane Alicia & USA & 1,275 & 1,650 \\
\hline 6 & 1987 & Winterstorm & Western Europe & 3,100 & 3,700 \\
\hline 5 & 1989 & Hurricane Hugo & Caribbean, USA & 4,500 & 9,000 \\
\hline 4 & 1990 & Winterstorm Daria & Europe & 5,100 & 6,800 \\
\hline 16 & 1990 & Winterstorm Herta & Europe & 1,300 & 1,900 \\
\hline 8 & 1990 & Winterstorm Vivian & Europe & 2,100 & 3,250 \\
\hline 15 & 1990 & Winterstorm Wiebke & Europe & 1,300 & 2,250 \\
\hline 3 & 1991 & Typhoon Mireille & Japan & 5,200 & 6,000 \\
\hline 11 & 1991 & Oakland fire & USA & 1,700 & 2,000 \\
\hline 1 & 1992 & Hurricane Andrew & USA & 20,000 & 30,000 \\
\hline 12 & 1992 & Hurricane Iniki & Hawaii & 1,600 & 3,000 \\
\hline 10 & 1993 & Blizzard & USA & 1,750 & 5,000 \\
\hline 19 & 1993 & Floods & USA & 1,000 & 12,000 \\
\hline 2 & 1994 & Earthquake & USA & 12,500 & 30,000 \\
\hline 7 & 1995 & Earthquake & Japan & 3,000 & 100,000 \\
\hline 18 & 1995 & Hailstorm & USA & 1,135 & 2,000 \\
\hline 14 & 1995 & Hurricane Luis & Caribbean & 1,500 & 2,500 \\
\hline 9 & 1995 & Hurricane Opal & USA & 2,100 & 3,000 \\
\hline 13 & 1996 & Hurricane Fran & USA & 1,600 & 3,000 \\
\hline
\end{tabular}


18 such events, 16 of them since 1990. Of these, Hurricane Andrew is the clear leader with insured losses of some US $\$ 20$ billion, which, however, would have been much higher had Andrew not landed a "double miss" but had achieved two direct hits in Miami and New Orleans. The same is true of the 1994 earthquake in California, which only skirted the edge of Greater Los Angeles and, in spite of projected insured losses of more than US\$ 12 billion, can only be considered a "warning shot".

The loss trend since 1960 (see Figure 1) clearly shows the dramatic increase in catastrophe losses in the last few years - a development that could well see average annual loss burdens from great natural disasters rise to US\$ 30-50 billion (in today's values) by the end of the decade. The increase compared to the 1960 s, which in the 1980 s amounted to a

Figure 1: Great Natural Disasters - 1960-1996
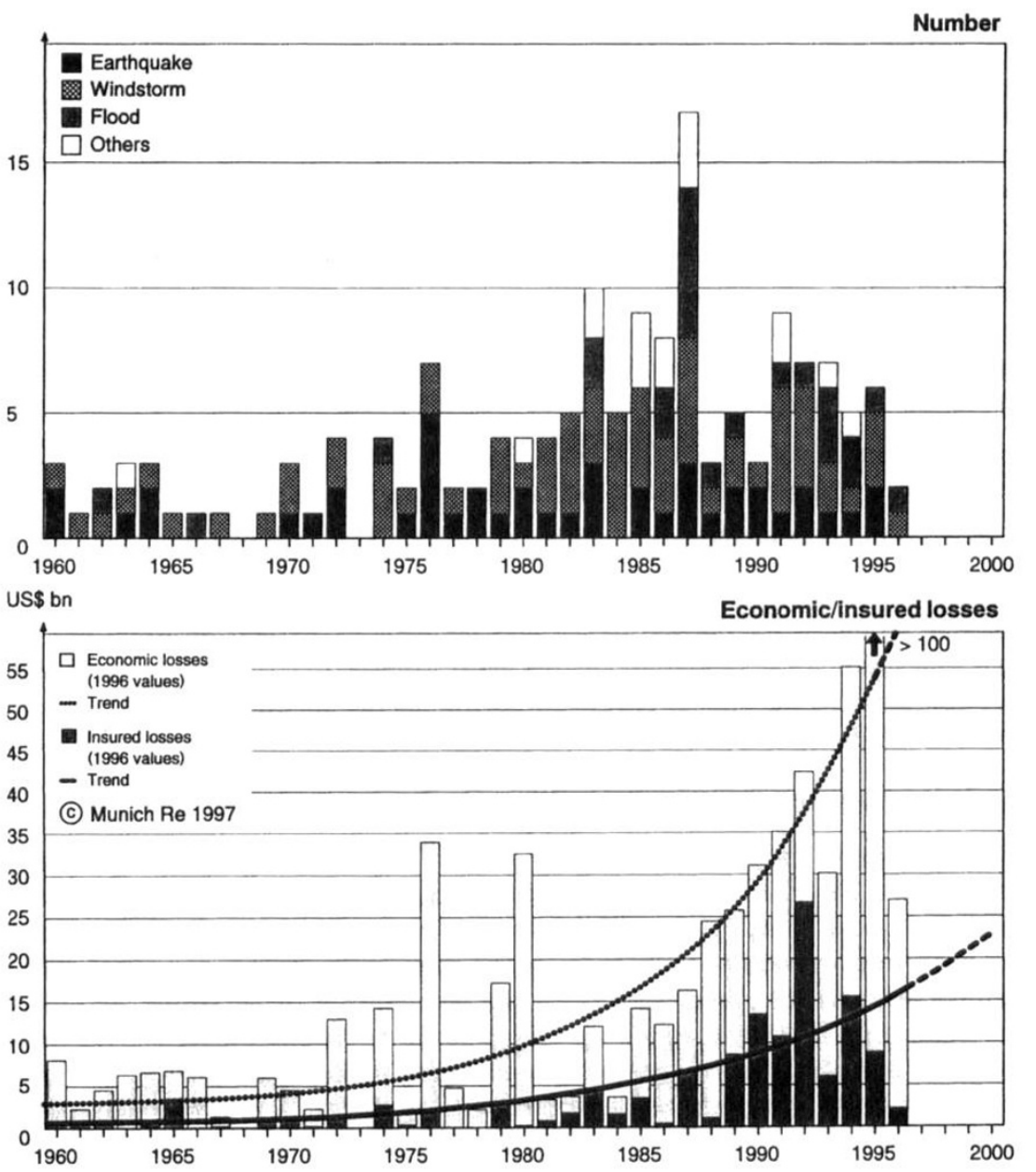
factor of three for economic losses and a factor of five for insured losses, has since escalated to factors of eight and fifteen respectively (see Table 2). These data are based on "great" natural disasters; the remaining natural loss events, hundreds of which are recorded each year, at least double the overall loss volume [5]

Table 2: Great Natural Disasters 1960-1996

\begin{tabular}{|l|c|c|c|c|c|c|}
\hline & $\begin{array}{c}\text { Decade } \\
1960-1969\end{array}$ & $\begin{array}{c}\text { Decade } \\
1970-1979\end{array}$ & $\begin{array}{c}\text { Decade } \\
1980-1989\end{array}$ & $\begin{array}{c}\text { Last ten years } \\
1987-1996\end{array}$ & $\begin{array}{c}\text { Factor } \\
80 \mathrm{~s}: 60 \mathrm{~s}\end{array}$ & $\begin{array}{c}\text { Factor } \\
\text { last ten : 60s }\end{array}$ \\
\hline Number & 16 & 29 & 70 & 64 & 4.4 & 4.0 \\
\hline $\begin{array}{l}\text { Economic } \\
\text { losses }\end{array}$ & 48.4 & 93.0 & 147.6 & 404.4 & 3.0 & 8.4 \\
\hline $\begin{array}{l}\text { Insured } \\
\text { losses }\end{array}$ & 6.5 & 10.9 & 29.8 & 98.8 & 4.6 & 15.2 \\
\hline
\end{tabular}

Loss figures in US-\$ billion (1996 values)

Without doubt, this rise in losses is caused to a great extent, if not to an overwhelming extent, by increasing economic values and insured liabilities, especially in heavily exposed areas. In addition, natural disasters have shown time and again that the loss susceptibility of buildings and infrastructures has rather increased than decreased, in spite of tighter building codes and other developments in technology. This fact has again been illustrated by Hurricane Andrew as well as by the Los Angeles and Kobe earthquakes.

\section{Indications of climate change}

At the same time, however, the evidence that emerging climate changes are having an ever greater influence on the frequency and intensity of natural disasters has become stronger. This has been demonstrated by the great windstorm disasters of recent years that have set new loss records almost every year as well as the countless flood, storm, drought and forest-fire disasters that seem to be occurring more often than ever before [1].

First of all, here are some facts about the changes in the atmosphere and on earth:

a) Without doubt the concentration of various climate-affecting trace gases in the atmosphere has risen significantly, which can only be attributed to the increased release of these gases by man. This is especially true of carbon dioxide, which has so far been responsible for about $50 \%$ of the man-made greenhouse effect. The other half comes from the greenhouse gases methane, nitrous oxide, ozone, and the CFCs, the chlorofluorocarbons, which are also known as "ozone killers". With their very long life periods all these gases have collected in the atmosphere and have thus, increased their concentration appreciably, as figure 2 shows. One important greenhouse gas has to be dealt with separately, namely water vapour. Without this 
Figure 2: Increases in greenhouse gases and world population growth

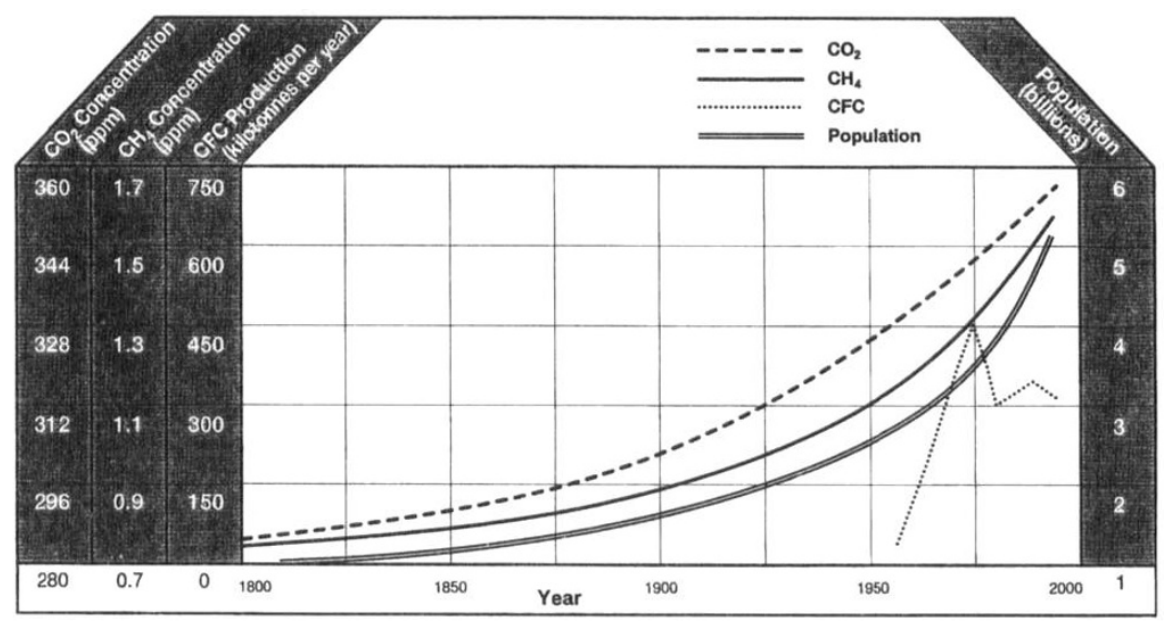

Source: Enquele Commission German Bundestag. 1891

REFIOEO 0296

gas the earth's surface would be 20 degrees colder, as $2 / 3$ of the natural greenhousewarming effect of 30 degrees comes from water vapour. This natural greenhouse effect, which significantly reduces the earth's long-wave radiation by means of the atmosphere absorbing and emitting this radiation back to the earth, first made life possible on earth. It is still unclear whether man has already significantly changed the water vapour content of the atmosphere.

b) There is no doubt that the ozone content of the stratosphere has steadily decreased in the last few decades (see Figure 3). Over the Antarctic some layers have no ozone

Figure 3: Ozone Content over the Antarctic (October means in Dobson units $=0.01 \mathrm{~mm}$ )

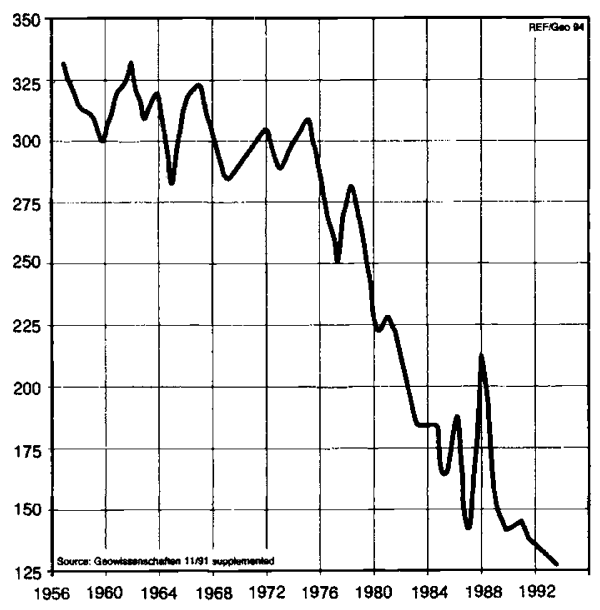


left whatsoever for certain periods of the year. The hole in the ozone layer is becoming ever bigger and deeper. Fortunately, however, on account of the required temperatures of below $-80^{\circ} \mathrm{C}$, this dramatic ozone depletion is still restricted to the uninhabited Antarctic and to a period of 4-6 weeks in the spring. However, densely populated areas of the northern hemisphere are also already showing signs of steady ozone depletion in the stratosphere (see Figure 4), which at $10 \%$ has not yet

Figure 4: Atmospheric ozone content

Observed and predicted relative changes

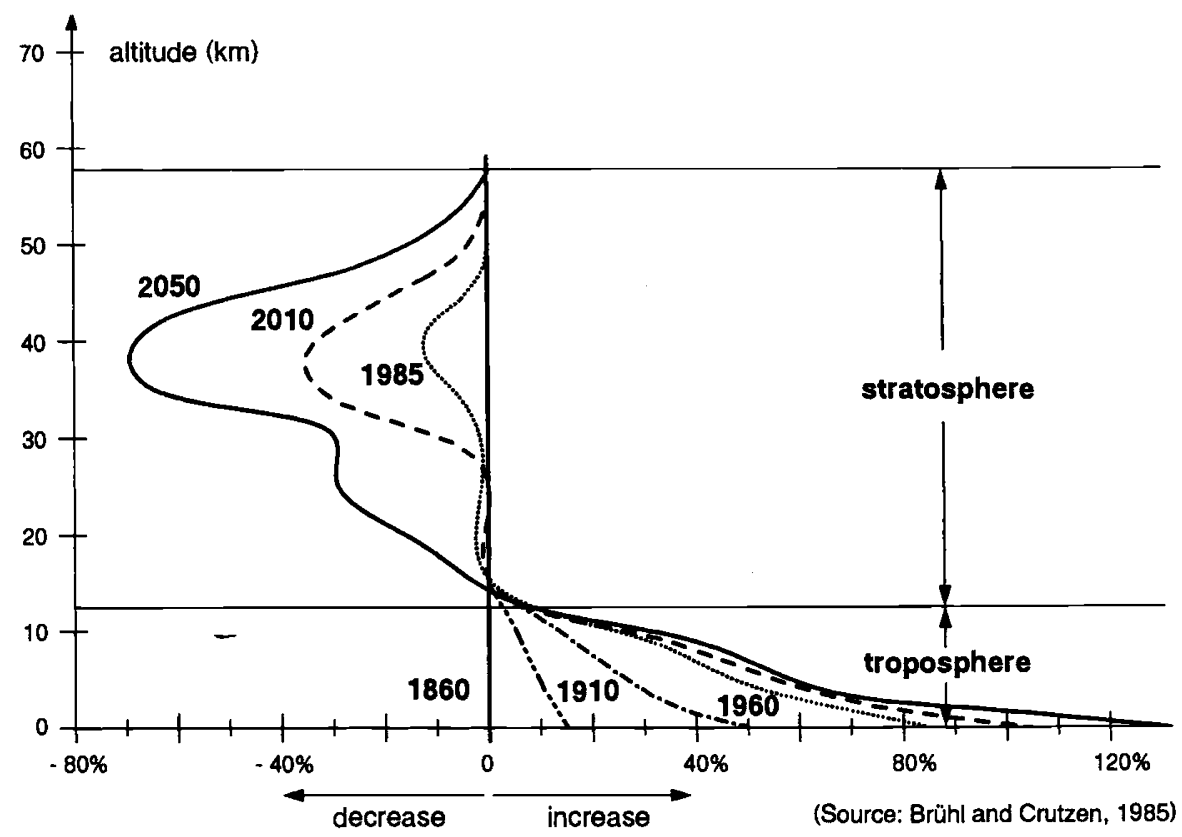

assumed any extreme levels. At the same time, a steady increase in low-altitude ozone concentration in all industrial areas has been observed, ozone smog, which occurs in urban areas during periods of intense sunshine. While CFCs have been proved to be the main cause of the hole in the ozone layer, ozone smog is mainly triggered by car exhaust fumes. Both phenomena are positively interlinked, i.e. they intensify each other, so that an increase in the harmful effects on humans, animals and plants can be expected.

c) The air is becoming increasingly turbid throughout the world, especially in industrial regions. This is due to aerosols, tiny particles of dust, soot and sand as well as droplets from condensed exhaust gases such as sulphur dioxide, as they diffuse sunlight more strongly and give the atmosphere a "milkier" appearance. At the same time, aerosols assist the condensation of water vapour and the formation of clouds, which then appear whiter. Consequently, more sunlight is reflected back to space from the surface of the clouds and less reaches the earth's surface (see Figure 5). This weakens 
Figure 5: Mean annual short-wave radiation

(Meteorological Observatory, Hohenpeißenberg / Germany)

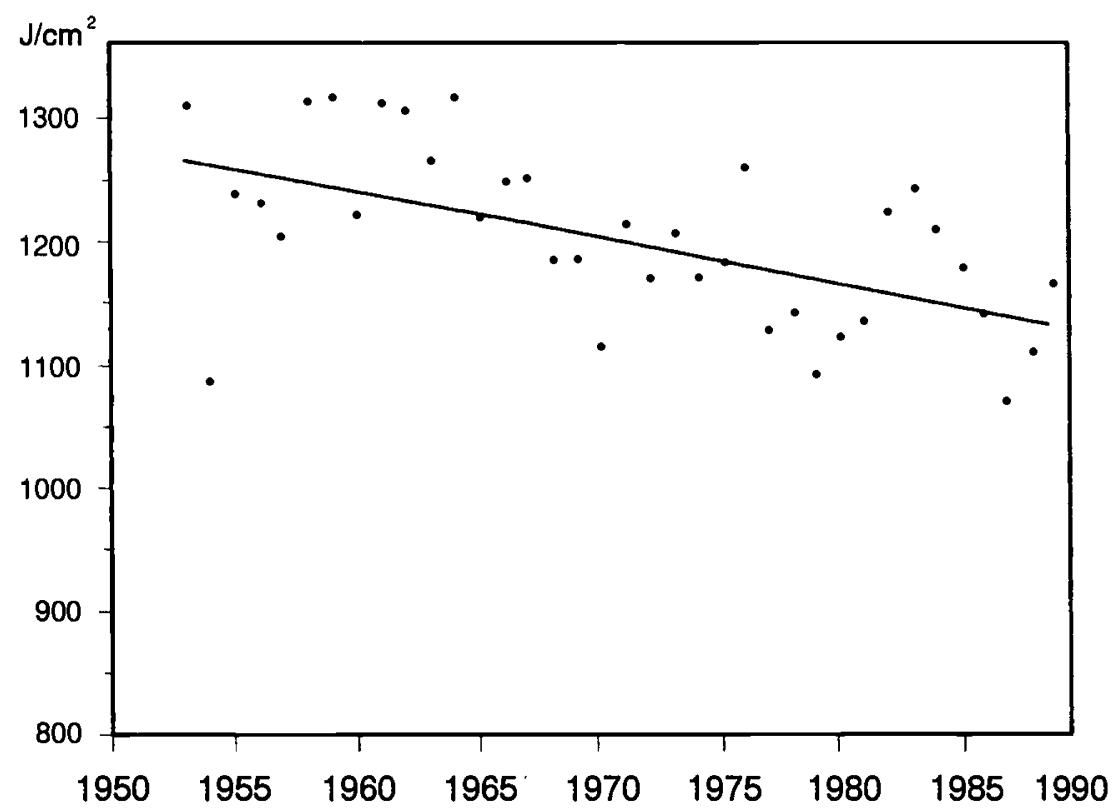

the greenhouse effect during the day, or rather "disguises" its true strength. At night, on the other hand, the long-wave emission of the atmosphere to the earth is intensified by the aerosols, which reduces the cooling effect of the night. And in actual fact, an increase in night temperatures has been observed worldwide while daytime temperatures have only shown slight changes. It is a similar case with the course of annual temperatures: warming has so far mainly taken place in winter.

d) Natural phenomena, such as eruptions of volcanoes, can also temporarily reduce the radiative budget of the lower atmosphere. This was, for example, the case after the eruption of Pinatubo in 1991 in the Philipines when some 7 cubic $\mathrm{km}$ of ash and gases were catapulted to a height of more than $20 \mathrm{~km}$ and the areosols in the stratosphere increased by a factor of 100 over large areas. This significantly reduced the shortwave radiation for several years and even the average global temperature temporarily sank by a several tenths. The aerosols have since fallen back to earth or have been washed out by rainfall, so that temperatures will soon reach and exceed their previous level.

e) Extreme melting of mountain glaciers has been observed worldwide, and has already assumed dramatic proportions in certain regions. Since their highest levels in the middle of last century, the Alpine glaciers have lost around $1 / 3$ of their surface and more than half of their mass. The discovery of "Otzi" is an obvious indication that the glaciers have not retreated as much for thousands of years. At the current melting 
rate, by the middle of next century there will only be lamentable traces of the once great Alpine glaciers. Large parts of Europe will thus lose their most important source of drinking water.

f) The melting of the glaciers causes the sea level to rise. Added to this is the thermal expansion of the sea water due to rising temperatures. The total rise in the sea level this century is $10 \mathrm{~cm}$, an amount that may seem low but does give cause for concern when it is seen as a sign of what is to come in the future.

g) The global rise in temperature of approximately 0.5 degrees (see Figure 6) also appears harmless at first even if the last decade produced the highest temperatures

Figure 6: Global mean temperatures since 1861

Yearly deviations from average value (1951-1980) and running mean

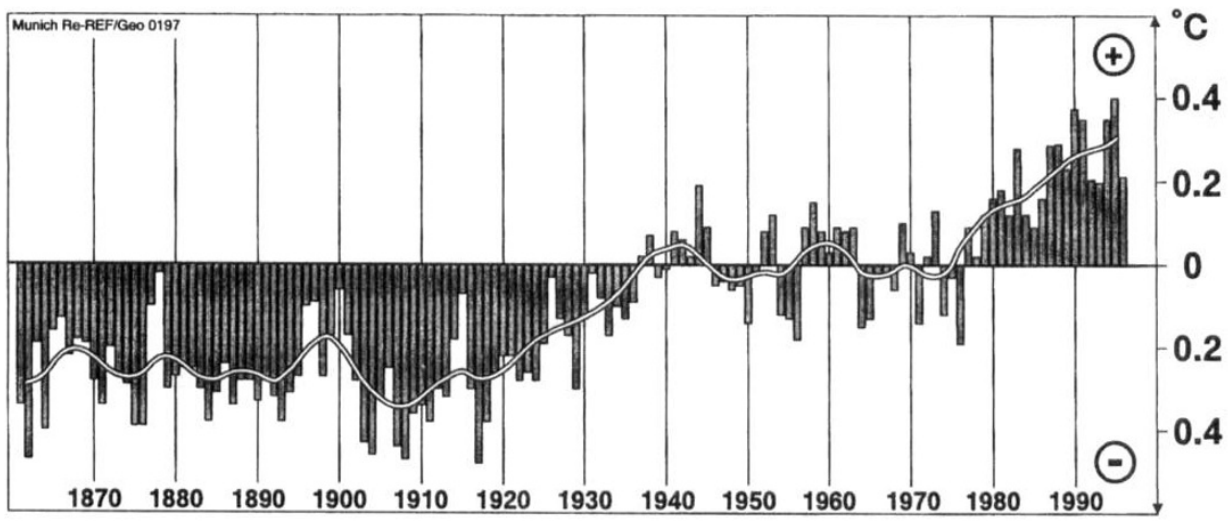

since worldwide meteorological records began 130 years ago. It is only when one considers that the differences between the cold and the warm periods in recent climatic history were on average only 5 degrees that the real significance of this warming becomes apparent. Added to this is the fact that the temperature rise in the lower atmosphere contrasts with an even sharper temperature drop in the stratosphere (the energy in the lower atmosphere is absent in the stratosphere), which reduces the stability of the stratification of the atmosphere and at the same time increases the destruction of the ozone layer.

h) There is a considerable delay before ocean temperatures follow the temperature rise in the atmosphere. This is because the oceans can store a great deal of warmth and the deep-sea water circulates on a type of huge conveyor belt roughly only once every thousand years. Nevertheless, significant rises in temperature have been observed even in large ocean areas - most recently in the western Pacific warm water pool, which has the effect of a gigantic heat source. Higher ocean temperatures lead to exponentially higher evaporation and to a correspondingly higher water vapour content in the atmosphere. This assists the development of high rainfall intensities and tropical cyclones. 
i) Warming is in no way evenly spread across the earth, indeed there are numerous regions which have even cooled down. Consequently, in some areas, such as over the northern Atlantic, the differences in temperatures and air pressures have grown (see Figure 7), resulting in a significant increase in windstorms in these areas in the last few decades. At the same time, the winters in Europe have become milder with the result that the eastern European high-pressure system, which builds up in winter over the large snow-covered surfaces of Europe, has weakened on average and retreated eastwards (see Figure 8). It is thus losing more and more of its blocking effect on the

Figure 7: Trend of atmospheric surface pressure ( $\mathrm{hPa})$ Winter, 1961-1990

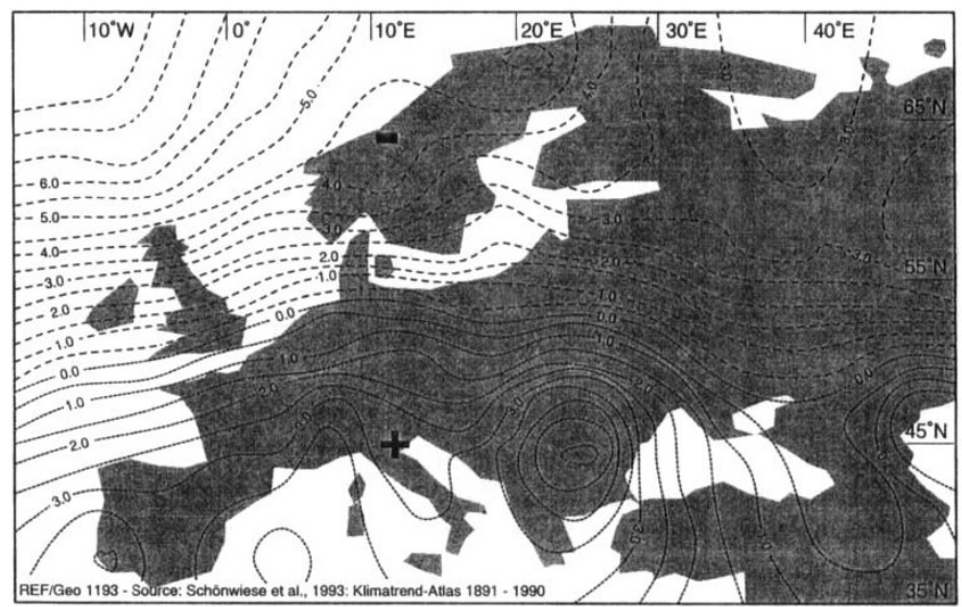

Figure 8: European winter storm tracks

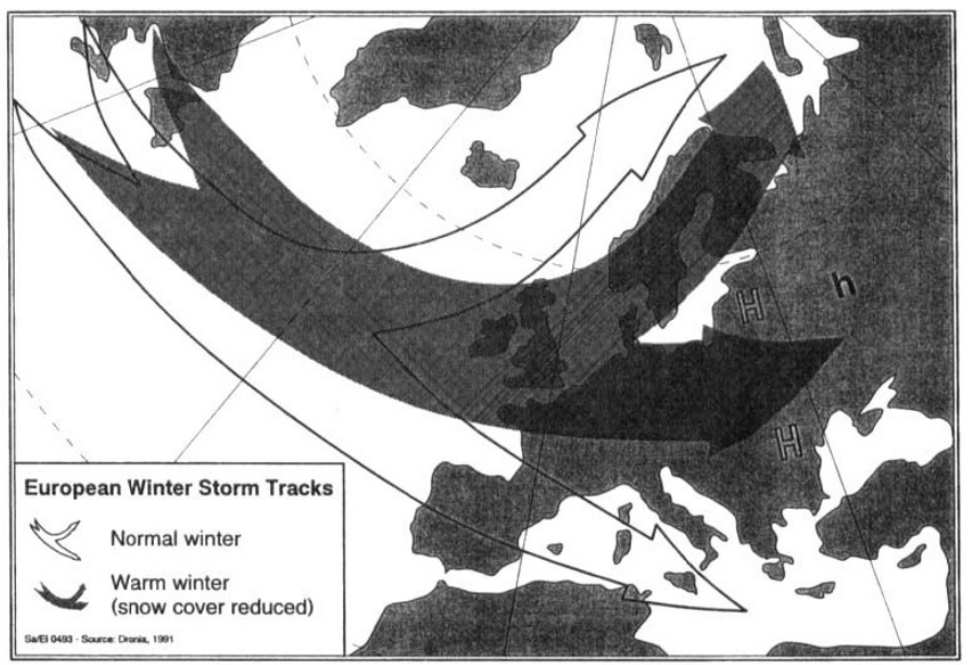


low-pressure systems approaching from the Atlantic, which are now able to penetrate more frequently and further eastwards and hit Europe with their hurricane-force winds, as was the case in January/February 1990.

j) Many other changes have affected the earth, such as the expansion of deserts and the increase in droughts on the edge of these areas, remarkable changes in flora and fauna-from increased wintering of former migratory birds in our latitudes to forests dying - and not least the increase in tropical diseases outside the areas where they are normally found. Climate change is usually only one of the many reasons for the numerous changes that are taking place in environmental and living conditions.

The decisive question is not whether this long list of evidence is conclusive but whether the climate data and computer climate models can provide enough information to allow sufficient time to assess future changes and develop the appropriate adjustment and preventive strategies. The risk of error will remain great for the foreseeable future. It is therefore all the more important that the strategies themselves can be adjusted and do not lead down any blind alleys. Successful from the very outset are socalled "no-regret" strategies such as the reduction of fuel consumption for cars or the reduction of energy consumption in general, as (even if the relevance to climate is lower than expected) they result in desirable savings and are also very useful to demonstrate to the Third World the industrialized countries' sense of responsibility.

\section{Climate change predictions}

But what sort of future do climatologists predict? The most reliable forecasts seem to be those made by the "Intergovernmental Panel on Climate Change", IPCC for short, as the many climatologists from all over the world that work together in this group are much less likely to make fundamental errors in their statements than individual scientists, who often have quite contradictory opinions. These conflicting opinions should not in any way be dismissed, as they often quite rightly take issue with factors in the forecasts with a considerable degree of uncertainty. Unfortunately, however, they also serve to provide decision makers in the political and economical worlds with convenient and at this present time most welcome excuses for a failure to act or a failure of policies.

The IPCC reports of 1990 and 1995 [2] extrapolate future development on the basis of various scenarios, of which the most plausible "the business as usual scenario", is considered the worst possible case. But is this really true? In view of the rising economic problems in the most heavily populated regions of the Third World, should it not be expected that the release of greenhouse gases will rise even more quickly in the future than has so far been the case? If this is true, the expected doubling of the carbon dioxide content by the middle of next century could well be too optimistic. There also has to be a large question mark over the assumed growth rates of the other greenhouse gases. Only the agreed phasing out of CFCs seems to be going as planned, even if new production plants are going into operation in some countries and the safety of the substitutes is not yet guaranteed.

According to the IPCC, the average global temperature will have risen by several degrees by the end of the next century. However, the lower curve in Figure 9 does seem unrealistic on account of the above-mentioned reasons. The area of uncertainty ranges 
Figure 9: Global rise of surface temperature

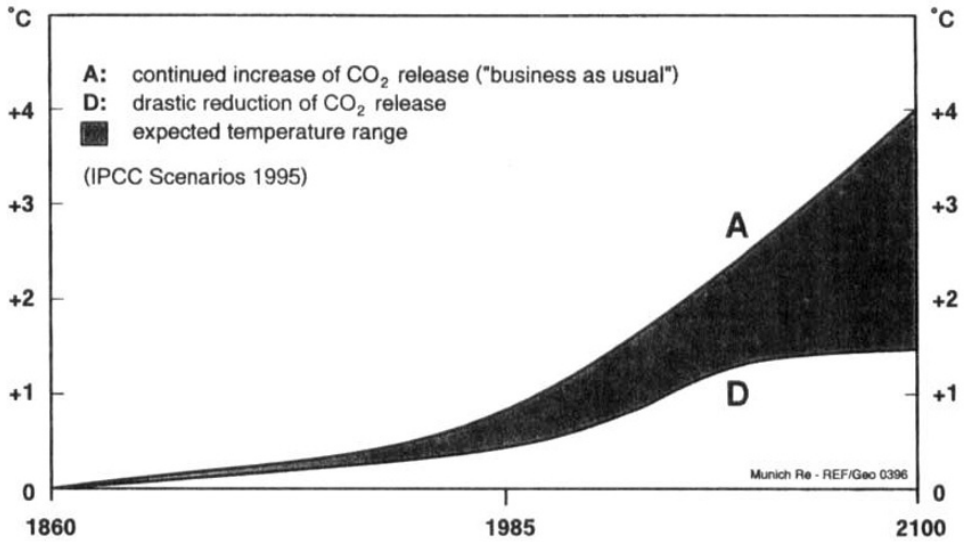

from about 1 to 4 degrees. This means an average global rise in temperature of some 0.2 degrees per decade and thus represents a significant acceleration over the 0.5 degrees in 100 years observed so far. The acceleration is so great that many ecosystems will probably not be able to adjust quickly enough.

The above-mentioned thermal slowness of the oceans and the buffer effect of the increase in snowfall in the Antarctic will cause the sea level to rise slightly more slowly than the previously assumed level of approximately $65+-30 \mathrm{~cm}$ in 100 years. This will not change the dramatic melting of inland glaciers in most mountainous regions of the world. Equally dramatic is the increase in humidity as a result of increased evaporation, as this has a decisive influence on precipitation and convective processes. We can therefore not only expect more torrential rain, flash floods and mudflows but also more thunderstorms, hailstorms, lightning and tornadoes. Tropical cyclones - including hurricanes and typhoons - may also be influenced by sea surface warming in their intensity, frequency, length of season and areas of occurrence. Extratropical storms, i.e. winter storms, are also likely to become more severe and, as explained above, penetrate further inland. In conjunction

Table 3: The present problems will be strongly aggravated if the climatic change predictions come true

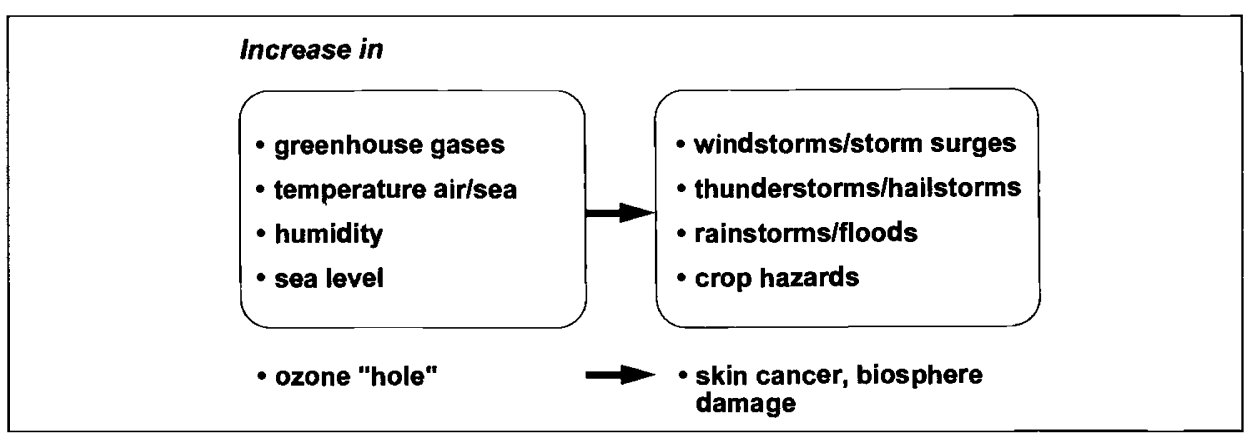


with the rise in sea level, increased windstorm activity will result in a sharp increase in the risk of storm surges for many coastal areas [3]. Table 3 summarizes all these effects.

\section{Effects and costs of global warning}

As climatic history can show us, a warmer global climate generally means more precipitation. In the long term the moderate and subpolar regions will profit from this while the areas which form the breadbaskets of the world will suffer from more frequent droughts. Even if the rising $\mathrm{C} 02$ content of the atmosphere improves growth conditions for most plants and their water requirements fall, this will be outweighed in many countries by the negative effects on agriculture, chiefly due to the exacerbated effect of heat and aridity. The winners will be those countries that can adapt their agriculture most quickly to the changing conditions, and these are obviously the highly developed coun tries, while the less developed ones will fall further and further behind.

However, not all effects have to be negative. For example, many countries in the moderate and subpolar regions of the world will be able to radically reduce their heating costs and the risk of frost will also be greatly diminished. Against this, other regions will see summertime energy consumption for air-conditioning systems rise significantly and more frequent heatwaves will cause additional damage.

Attempts have been made recently to estimate the worldwide costs of the man-made greenhouse effect and to take appropriate stabilizing measures. The results are quite clear: According to an investigation by the Fraunhofer Institute for Systems Engineering on behalf of the EU [4], the probable losses from climate change will increase up to a figure of DM 10,000 billion per year by the end of the next century. However, permanent preventive strategies would reduce this by half. In spite of this, many governments and economic enterprises still seem to be undecided about or even opposed to the Framework Convention on Climate Change signed in Rio in 1992. The next Climate Summit, which is being held in Kyoto in December 1997, will show whether the 190 or so signatory states are really serious about their decision regarding measures to protect the climate.

An interesting question could be which climate should be sought as the most favourable for the whole earth. On the other hand, there is absolutely no question that the global experiment that man has attempted in such an aimless and uncontrolled fashion will have to be brought under control as soon as possible if later generations are not to inherit a completely destabilized climate. If the problem of climate change is seen from this ethical point of view, there can be no doubt whatsoever that it is high time something was done. As the climate changes witnessed so far and those predicted for the future have been caused in the main by the industrial nations, it is only right that they should also bear the main responsibility for developing and implementing the necessary countermeasures.

\section{Impact on the insurance industry and possible countermeasures}

Confident in its exceptional ability to adjust to changing risk circumstances, the insurance industry could now adopt the attitude that it is not really affected by climate change. However, I must strongly warn against such an attitude. It is to be feared that climate change will produce in nearly all regions of the world new extreme values of many insurance-relevant parameters that will lead to natural disasters of unprecedented severity 
Table 4

\section{Climate change may have significant impacts on the insurance industry:}

- Increase in weather variability

- New extreme values in certain regions

- New exposures

- More frequent and larger natural disasters

- Greater claims potential

- Poorer claims experience

- Lagging premium adjustment

and frequency. This will cause capacity problems in national and international insurance markets that are much more serious than those experienced in the last few years. The whole future of this class of business in certain regions could be at stake if the development of this problem is misjudged. And premium income would also lag behind loss development in this case (see table 4).

On the other hand, it is possible for the insurance industry to protect itself adequately against the effects of climate change and at the same time make a significant contribution to implementing measures to protect the climate. No other sector of the economy has such effective instruments for encouraging risk reduction. However, this can only work if the insurance industry can have its clients and the authorities as useful partners on its side. If, for example, insurers can convince their clients that substantial deductibles in natural hazards insurance are of benefit to both sides because they relieve insurers from the great number of minor losses, which can be more effectively remedied by clients, and because they substantially reduce the price of cover, clients will then be more willing to take measures that prevent or minimize losses. If, on the other hand, the insurance industry

Table 5

The proper response of the insurance industry to the deteriorating environmental conditions must include

- Sound technical pricing

- Significant deductibles

- Appropriate liability limits

- Transparency / accumulation control

- Loss prevention / mitigation

- Awareness / education 
looks at the growing loss potential and decides to exclude certain perils or risk areas from cover or severely restrict the scope of cover, then the pressure will inevitably grow on authorities to take measures to improve risks or to tackle the cause of losses or even to transfer the risk from the welfare system to the government (see table 5).

It would, however, be wrong if the insurance industry were to take on the state's role of penalizing or rewarding environmen tally-damaging or environmentally-friendly conduct on the part of its clients. This cannot be the task of the insurance industry even if it were in its interests with regard to the correlation between environmental losses and natural disasters.

\section{Conclusion:}

Mankind is carrying out a huge experiment with the earth's climate, over which it has so far had practically no control and the outcome of which is still very much open. It could, however, dramatically effect mankind's living conditions in the future. As much as people can still argue today about the future development of climate change and in particular the effects it will have, this very high level of uncertainty is itself a great cause for concern. Even if the caution we are now showing proves to be unfounded, we have no choice if we are to behave responsibly towards later generations. We must try, with all available means, to ensure that, metaphorically speaking, the greenhouse window does not close even further.

\section{REFERENCES}

BERZ, G.: Global Warming and the Insurance Industry. Interdisciplinary Science Reviews, Vol. 18 (1993), No. 2, pp. 120-125.

Intergovernmental Panel on Climate Change: Policymakers Summary. Geneva, 1995.

BERZ, G. and K. CONRAD: Stormy Weather: The Mounting Windstorm Risk and Consequences for the Insurance Industry. Ecodecision, No. 12 (1994), pp. 65-68.

HOHMEYER, O. and M. GAERTNER: The Costs of Climate Change. Report to the Commission of the EU. Karlsruhe, 1992. 